http://jmscr.igmpublication.org/home/

ISSN (e)-2347-176x ISSN (p) 2455-0450

crossref DOI: https://dx.doi.org/10.18535/jmscr/v8i3.108

Journal Of Medical Science And Clinical Research

IGM Publication

An Official Publication of IGM Publication

\title{
Correlation between Body Mass Index and Glycated Hemoglobin (HbA1c) Level in Patients of Type 2 Diabetes Mellitus
}

\author{
Authors \\ Razook Fareedh .J ${ }^{1}$, Suresh.K $\mathbf{K}^{\mathbf{1}}$, Muraliswaran. $\mathbf{P}^{\mathbf{2}}$ \\ ${ }^{1}$ Department of General Medicine, Sri Venkateshwaraa Medical College Hospital and Research Centre, \\ Pondicherry, India \\ ${ }^{2}$ Department of Biochemistry, Sri Venkateshwaraa Medical College Hospital and Research Centre, \\ Pondicherry, India
}

\section{Introduction}

Diabetes mellitus is one of the most common diseases of current era which is characterized by hyperglycemia either due to insulin deficiency or insulin resistance. Type $2 \mathrm{DM}$ is also leading cause of coronary artery disease, peripheral artery disease, end-stage renal disease (ESRD) and adult blindness. With an increasing incidence worldwide, DM will be a leading cause of mortality and morbidity ${ }^{[1]}$. The explosive increase of Diabetic population worldwide is a major public health concern both in developing and developed countries. Metabolic syndrome is also on an increasing trend. The metabolic syndrome is closely linked to insulin resistance and numerous studies indicate a link to iron overload. Increased serum ferritin, reflecting body iron overload, is often associated with measures of insulin resistance, such as elevated blood glucose and insulin levels ${ }^{[2]}$.

Obesity is a state of excess adipose tissue mass. ${ }^{[3]}$ However, in the presence of nutritional abundance and a sedentary lifestyle, and influenced importantly by genetic endowment, this system increases adipose energy stores and produces adverse health consequences . According to WHO global obesity almost doubled between 1980 and 2008. There were $>200$ million obese men and almost 300 million obese women, $11 \%$ of adults worldwide, in 2008. ${ }^{[3]}$ In developing countries, such as India obesity prevalence is rising (5\%) with a greater tendency to harmful intraabdominal obesity at lower BMI in the population, and the consequences for metabolic and cardiovascular health are disproportionate to obesity prevalence. ${ }^{[3]}$ Although not a direct measure of adiposity, the most widely used method to gauge obesity is the Body Mass Index (BMI), which is equal to weight/height (in $\mathrm{kg} / \mathrm{m} 2$ ).

Glycated Hemoglobin (HbA1c) is a routinely used marker for long-term glycemic control

Hence our study was aimed to establish a correlation between Body Mass Index with glycated Hemoglobin level in patients with type 2 diabetes mellitus.

Diabetes mellitus (DM) is a group of metabolic diseases characterized by hyperglycemia resulting from defects in insulin secretion, insulin action, or both. The various factors which can contribute to hyperglycemia include reduced insulin, decreased 
glucose utilization and increased glucose production. DM is one of the leading causes of morbidity and mortality in human population ${ }^{[4]}$. Although the prevalence of both type 1 and type 2 DM is increasing worldwide, the prevalence of type $2 \mathrm{DM}$ is rising rapidly because of increase in obesity and reduced physical activity as countries are becoming more industrialized. Metabolic disturbances associated with DM includes impaired glucose tolerance, insulin resistance, gestational diabetes, malnutrition or over nutrition and other risk factors like hypertension, polycystic ovarian syndrome and dyslipidemia ${ }^{[5]}$.

Glycated hemoglobin concentration represents the integrated values of glucose over preceding 6 to 8 weeks since the rate of formation of $\mathrm{HbA} 1 \mathrm{c}$ is directly proportional to the concentration of glucose in blood.

It is currently considered as the best index of metabolic control for diabetic patients in clinical setting. It is as well a measure of risk for the development of micro and macrovascular complications. $^{[6,7]}$

The most important factor governing the quantity of glycated hemoglobin formed is the prevailing plasma glucose concentration. As the plasma glucose concentration is increased in diabetic subjects, glycated hemoglobin also increased in diabetic subjects. ${ }^{[8]}$

It represents the mean daily blood sugar concentration and degree of carbohydrate imbalance, better than fasting blood glucose concentrations or glucose tolerance test results. Hence it may provide a better index of control of diabetic patient without resorting to a glucose loading procedure. ${ }^{[8]}$

\section{Aim and Objectives}

The aim of this study is to establish a

Correlation between Body Mass Index and Glycated Hemoglobin (HbA1c) Level in Patients of Type 2 Diabetes Mellitus

\section{Method and Materials}

The present study was aimed to establish a correlation between Body Mass Index with glycated Hemoglobin level in patients with type 2 diabetes mellitus diabetic patients was carried out in Sri Venkateshwaraa medical college hospital and research centre which is a 750 bedded multi disciplinary centre serving the rural population. The study was carried out in the department of General Medicine in association with diabetology.

Type of Study: Cross-sectional study

Period of Study: From NOV 2017 to MAY 2019

Study Population: Patients with Type 2 Diabetes Mellitus selected by random sampling from those admitted in medical wards and those who present to Medicine OPD.

Sample Size: Sample size was calculated for correlation between $\mathrm{HbA} 1 \mathrm{c}$ and Body Mass Index in type 2 diabetes mellitus based on previous studies which showed that correlation coefficient (r) between $\mathrm{HbA} 1 \mathrm{c}$ and Body Mass Index was 0.66 , assuming $\alpha$ error of $1 \%$ and $\beta$ error of $10 \%$. Sample size was calculated to be 100 . So 50 diabetic and 50 non diabetic subjects will be included in the study. Group-I-Control; Group-

\section{II-TYPE 2DM}

\section{Inclusion Criteria}

Age between 35 to 70 years of both gender with type 2 diabetes mellitus

\section{Method of Data Collection}

All type 2 diabetic patients attending to medical and diabetology department in Sri Venkateshwaraa medical college hospital and research centre were included in the study after obtaining informed concern and description of the procedure. After documenting the demographic data of the patients a details clinical history and details of diabetes was obtained from the patients. A thorough general physical examination and a detailed systemic examination was obtained and documented as in Proforma.

\section{Interventions/Investigations Needed}

Sample Collection; After all the required procedures the patients were subjected for the investigations. The investigations done were HbAlc, and fasting blood sugar.

$5 \mathrm{~mL}$ of fasting blood sample will be collected and centrifuged for serum/plasma separation. 
Sample will be analysed for the measurement of plasma glucose by glucose oxidase-peroxidase method, whole blood will be taken in EDTA vial for $\mathrm{HbA1c}$ and serum ferritin will be assessed by ELISA method by commercially available kit.

Measurement of Fasting Blood Glucose: Serum concentration of glucose was estimated by using analytical kits from Erba Diagnostics Mannheim $\mathrm{GmbH}$ in semi-auto analyzer (CHEM-5 Plus $\mathrm{V}_{2}$, Erba Mannheim).

Measurement of testing HbA1c: Glycated hemoglobin was estimated by Nephelometry kits from Agappe in MISPA-i card reader.

Measurement of Body mass Index: Body height in centimetres and body weight in kilograms $(\mathrm{kg})$ were measured with light clothes and bare feet, and $\mathrm{BMI}$ in $\mathrm{kg} / \mathrm{m} 2$ was calculated

Statistical Analysis: It will be done by using SPSS version 23.0

\section{Results}

A total number of 100 subjects have been studied. This includes 50 controls and 50 Type 2 Diabetic subjects.

1) Controls: 50

Males: 38

Females: 12

2) Type 2 Diabetic subjects : 50

Males: 34

Females: 16

Table: 1 Distribution of controls and diabetic cases as per age group

\begin{tabular}{|l|c|c|c|c|}
\hline \multirow{2}{*}{ Age in years } & \multicolumn{2}{|c|}{ Cases } & \multicolumn{2}{c|}{ Controls } \\
\cline { 2 - 5 } & $\mathbf{n}$ & $\mathbf{\%}$ & $\mathbf{n}$ & $\mathbf{\%}$ \\
\hline $31-40$ & - & - & 02 & 04 \\
\hline $41-50$ & 11 & 22 & 26 & 52 \\
\hline $51-60$ & 20 & 40 & 15 & 30 \\
\hline$>60$ & 19 & 38 & 07 & 14 \\
\hline Total $(\mathrm{n}=)$ & 50 & 100.0 & 50 & 100.0 \\
\hline Mean \pm SD & \multicolumn{2}{|c|}{$45.5 \pm 7.8$} & \multicolumn{2}{|c|}{$46.6 \pm 6.7$} \\
\hline
\end{tabular}

Figure: 1 Distribution of controls and diabetic cases as per age group

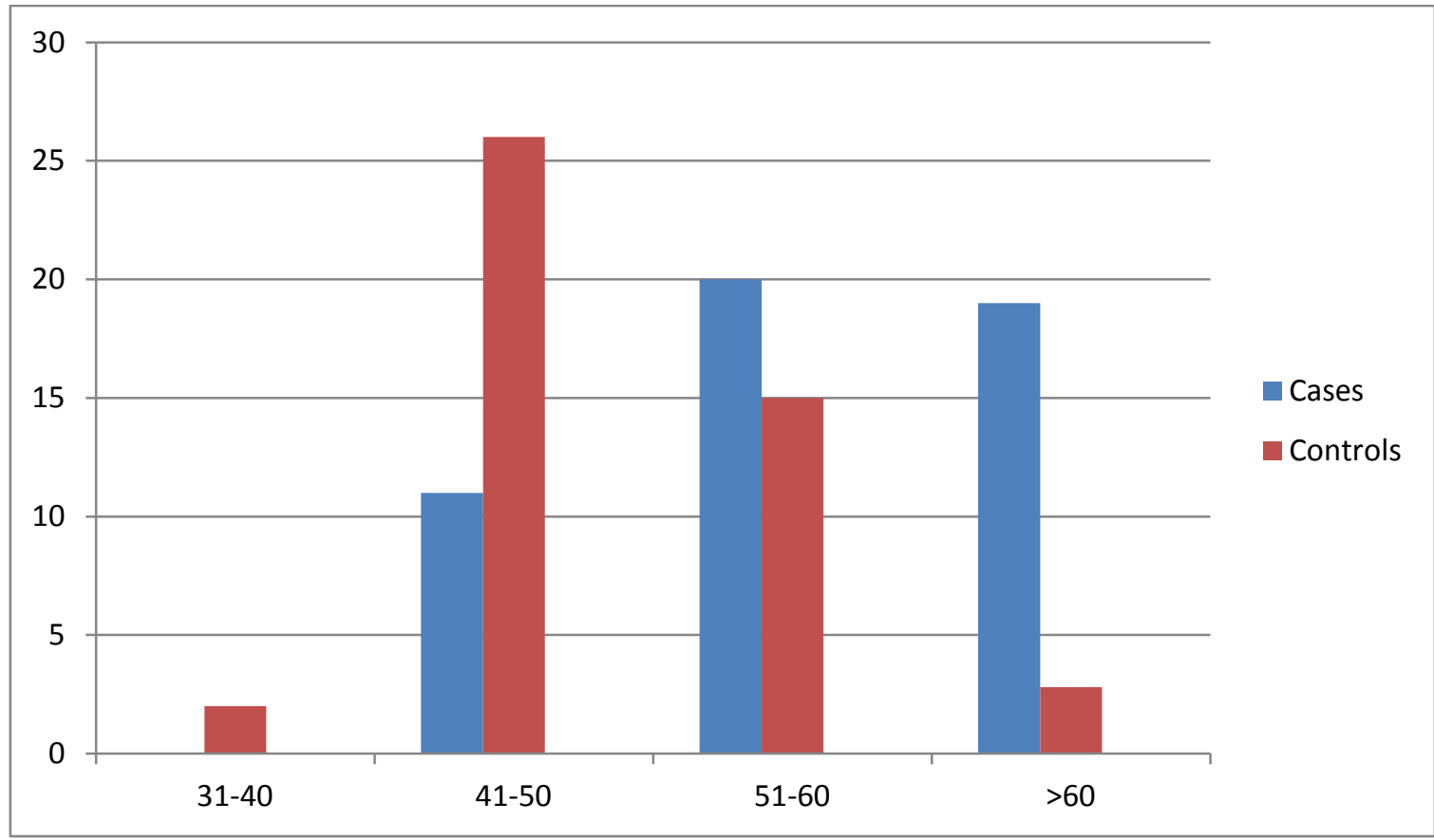

Table: 2 Gender wise Distribution

\begin{tabular}{|l|c|c|}
\hline Gender & Case & Control \\
\hline Male & 34 & 38 \\
\hline Female & 16 & 12 \\
\hline Total & 50 & 50 \\
\hline
\end{tabular}


Figure: 2 Gender wise Distribution

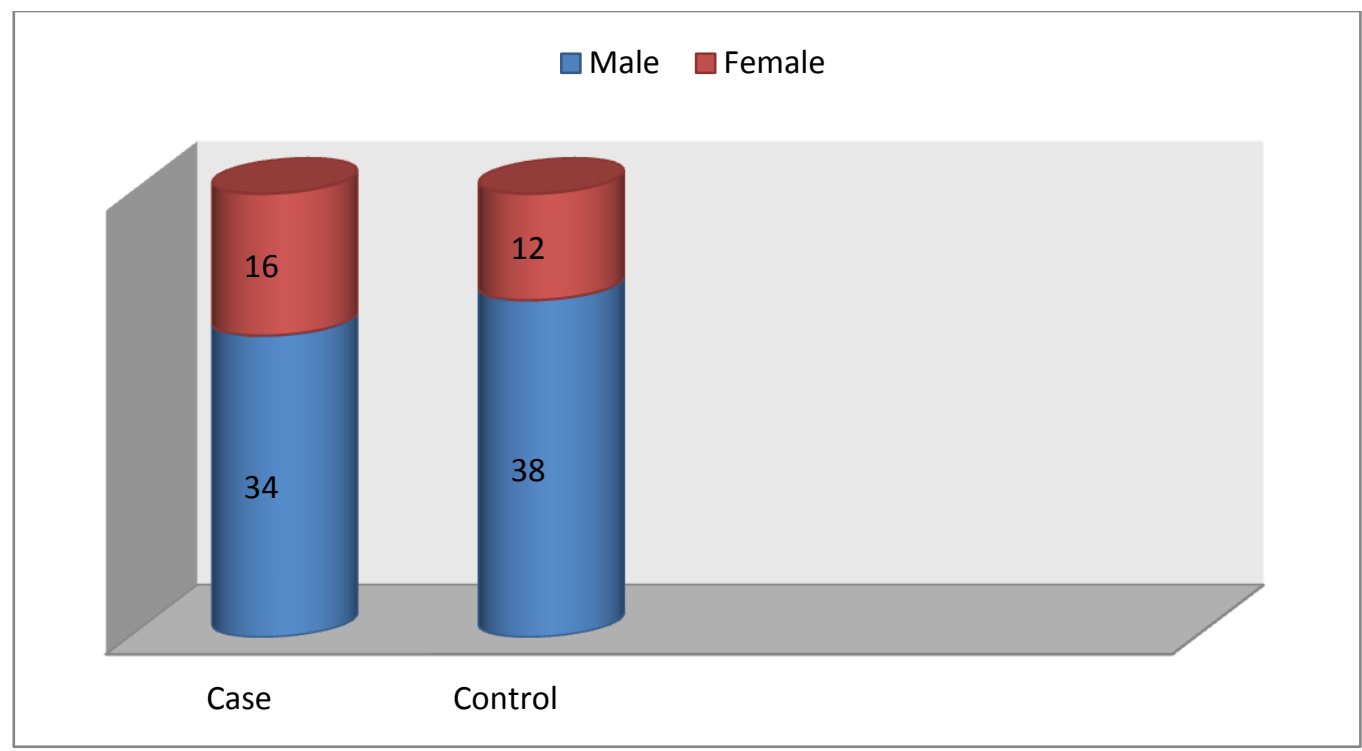

Table: 3 BMI $\left(\mathrm{kg} / \mathrm{m}^{2}\right)$ distribution in controls and diabetic cases

\begin{tabular}{|c|c|c|c|c|}
\hline \multirow[b]{2}{*}{ BMI $\left(\mathrm{kg} / \mathrm{m}^{2}\right)$} & \multicolumn{2}{|c|}{ Cases } & \multicolumn{2}{|c|}{ Controls } \\
\hline & No & $\%$ & No & $\%$ \\
\hline $18.6-22.9$ & 4 & 08 & 28 & 56 \\
\hline $23-25$ & 11 & 22 & 12 & 24 \\
\hline $26-30$ & 21 & 42 & 10 & 20 \\
\hline$>30$ & 14 & 28 & 0 & 0.0 \\
\hline Total & 50 & 100.0 & 50 & 100.0 \\
\hline Mean \pm SD & \multicolumn{2}{|c|}{$26.34 \pm 2.31$} & \multicolumn{2}{|c|}{$22.60 \pm 2.60$} \\
\hline
\end{tabular}

Figure: $3 \mathrm{BMI}\left(\mathrm{kg} / \mathrm{m}^{2}\right)$ distribution in controls and diabetic cases

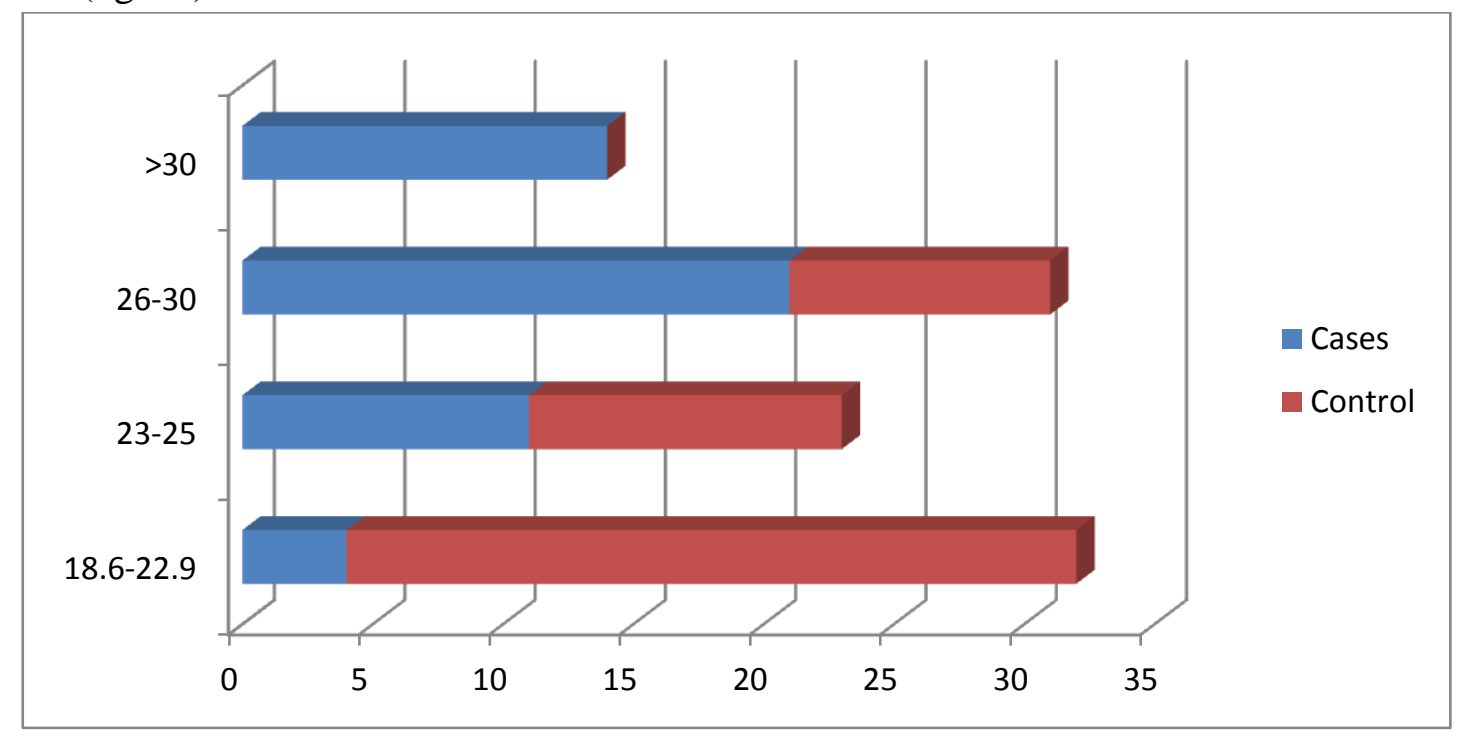

Table: 4 Fasting blood sugar level $(\mathrm{mg} / \mathrm{dl})$ in diabetics and controls (mean \pm S.D)

\begin{tabular}{|l|c|c|c|c|}
\hline \multirow{2}{*}{ FBS (mg/dl) } & \multicolumn{2}{|c|}{ Cases } & \multicolumn{2}{c|}{ Controls } \\
\cline { 2 - 5 } & No & $\mathbf{\%}$ & No & $\mathbf{\%}$ \\
\hline$<100$ & 0 & 0.0 & 50 & 100.0 \\
\hline $100-120$ & 04 & 08 & 0 & 0.0 \\
\hline$>\mathbf{1 2 0}$ & 46 & 92 & $\mathbf{0}$ & $\mathbf{0 . 0}$ \\
\hline Total & 50 & 100.0 & 50 & 100.0 \\
\hline Mean \pm SD & \multicolumn{2}{|c|}{$188.20 \pm 58.89$} & \multicolumn{2}{c|}{$90.93 \pm 6.27$} \\
\hline
\end{tabular}

$\mathrm{p}<0.001$ 
Table: 6 HbA1c wise Distribution

\begin{tabular}{|l|c|c|}
\hline & & HbA1c (\%) \\
\hline Controls & Mean \pm SD & $5.42 \pm 0.47$ \\
\hline Cases & Mean \pm SD & $8.59 \pm 1.83$ \\
\hline & p-value & $<0.001$ \\
Cases v/s Controls & Significance & HS \\
\hline
\end{tabular}

Table: 8 Shows Comparisons of HbA1c and BMI in Controls and Type 2 Diabetic Subjects

\begin{tabular}{|l|c|c|c|}
\hline & & HbA1c (\%) & BMI $\left(\mathbf{k g} / \mathbf{m}^{2}\right)$ \\
\hline Controls & Mean \pm SD & $5.42 \pm 0.47$ & $22.60 \pm 2.60$ \\
\hline Cases & Mean \pm SD & $8.59 \pm 1.83$ & $24.34 \pm 2.31$ \\
\hline Cases v/s Controls & p-value & $<0.001$ & $<0.001$ \\
& Significance & HS & HS \\
\hline
\end{tabular}

\section{Discussion}

The present study was carried out from NOV 2017 to MAY 2019, 750 bedded Multi-Speciality Teaching Hospital attached to Sri Venkateshwaraa medical college hospital and research centre.

In the present study we had evaluated 100 subjects including 50 controls and 50 type 2 diabetic subjects. Of the 50 type 2 diabetic subjects, 34 were males and 16 were females and among controls, 38 were males and 12 were females.

In our study it was found that maximum patients affected were male group under the age of 51-60 years (20 patients), followed by the age group of $>60$ years (19 patients), and the age group of 4150 years (11 patients). (Fig.Table-1). This is similar to various other study in our country some are, a study done by Ramesh Chandra Thanna et $\mathrm{al}^{[9]}$ the mean age of the study group was $54.5 \pm 8.5$ years, study done by Poonam Arora et $\mathrm{al}^{[10]}$ mean age of diabetic patients was $52.37 \pm 7.98$ years.

In our study we conclude that male patients dominated the both study and the control group. Male: female ratio was 68\%:32\% (Fig.Table-2). This is similar to other studies form our country, study done by Ramesh Chandra Thanna ${ }^{[9]}$ showed M:F - 64:36.

The mean \pm SDs of BMI in controls and type 2 diabetic subjects were in the range of $22.60 \pm 2.60$ $\mathrm{mg} / \mathrm{dL}$ and $26.34 \pm 2.31 \mathrm{mg} / \mathrm{dL}$, respectively. The mean value of BMI was higher in type 2 diabetic subjects compared to controls (Fig.Table-3). Various other studies done in our country demonstrated BMI among diabetic respectively; mean BMI was $24.85 \mathrm{~kg} / \mathrm{m} 2$ in Ramesh Chandra Thanna ${ }^{[9]}$ and mean BMI was $23.95 \pm 3.15 \mathrm{~kg} / \mathrm{m} 2$ in a study done by L. S. Patil et $\mathrm{al}^{[11]}$.

The mean \pm SDs of HbA1c in controls \& type 2 diabetes were in the range of $5.42 \pm 0.47 \& 8.59 \pm$ $1.83 \%$ respectively. (Table-6) The mean value of HbA1c was higher in type 2 diabetic subjects as compared to controls. The increase was statistically highly significant $(\mathrm{p}<0.001)$. This is in accordance with Dalan R et al $4.42 \pm 0.37 \& 7.59 \pm 1.43 \%$. ${ }^{[12]}$ The mean \pm SDs of ferritin in controls and type 2 diabetic subjects were in the range of $101.55 \pm$ $78.76 \mathrm{ng} / \mathrm{mL}$ and $263.34 \pm 82.65 \mathrm{ng} / \mathrm{mL}$ respectively. (Table-7) The mean value of ferritin in type 2 diabetic subjects was higher when compared to controls. The increase was found to be statistically highly significant ( $p<0.001)$. This is in accordance with the Sharifi $\mathrm{F}$ et $\mathrm{al}^{[13]} \&$ AbouShousha S.A. ${ }^{[14]}$

In the present study we also found positive correlation existed between BMI and $\mathrm{HbA} 1 \mathrm{c}$ in type 2 a diabetic subject which was statistically significant. (Table-8)This is in accordance with Shetty J.K et al ${ }^{[15]} \&$ Kim N.H et al. ${ }^{[16]}$

\section{Conclusion}

worsening metabolic state.

The study entitled "The Study of correlation between Body Mass Index (BMI) and glycemic control (HbAlc) in diabetes type 2 Patients"' is of cross sectional for a sample of 100 patients of type 2 Diabetes mellitus revealed that abnormal BMI (Obesity) were is the statistically significant found correlation with poor glycemic control (HbA1c). The BMI and HbA1c should be kept under strict control so that complications associated with diabetes would be delayed. 


\section{References}

1. Fauci AS, Kasper DS, Longo DL, Braunwald E, Hauser SL, Jameson JL, et al. Harrison's Principles of internal medicine. United State, 18th Edition 2012

2. Jiang R, Manson JE, Meigs JB, Ma J, Rifai $\mathrm{N}, \mathrm{Hu}$ FB. Body iron stores in relation to risk of type 2 diabetes in apparently healthy women. JAMA 2004; 291:711-7.

3. Flier JS, Maratos-Flier E. Pathobiology of obesity. In: Anthony S. Fauci, editor. Harrison's principals of internal medicine. 20th ed. New Delhi: McGraw-Hill Education; 2018:2837-2842.

4. Alvin C Power. Diabetes Mellitus. In: Fauci AS, Braunwald E , kasper DL, Hauser SL, Longo D, Jameson JL, et al, editors. Harrison's principles of internal medicine Vol 2.17 ${ }^{\text {th }}$ ed. New York: Mc Grawhill; 2008. p.2275-76

5. Pfutzner A, Schondorf T, Hanefeld M, Forst T. High Sensitivity C-Reactive Protein predicts cardiovascular risk in diabetic and nondiabetic patients. $\mathrm{J}$ Diabetes Sci Technol 2010;4(3):706-16

6. Burtis CA, Ashwood ER, Bruns DE. Teitz textbook of clinical chemistry and molecular diagnostics, $4^{\text {th }}$ ed. New Delhi; Saunders Harcourt: 2006.p.869-85

7. Makris K, Spanou L. Is there relationship between mean blood glucose and glycated hemoglobin. J Diabetes Sci Technol 2011;5(6):1572-583

8. Koeing RJ, Peterson CM, Kilocharles, Cerami Anthony, Williamson JR. Hemoglobin $A_{1 c}$ as an indicator of degree of glucose intolerance in diabetes. Diabetes 1976;25(3):230-32
9. Ramesh Chandra Thanna, Shreya Nigosker Level of Serum ferritin and Glycated hemoglobin (HbA1C) in type 2 diabetes mellitus. International Journal of Medical and Health Research. ISSN: 2454-9142.

10. Arora: Serum Ferritin in Type 2 Diabetes Mellitus Int J Cur Res Rev | Vol 9 • Issue 6 - March 2017.

11. L. S. Patil, Dr. Timmanna Giraddi, Dr. Deepak Chinagi, Dr. Prasad Ugaragol and Dr. Banashankari Kolluru, 2017. "A study on relation between serum ferritin and glycated hemoglobin in type 2 diabetes mellitus", International Journal of Current Research, 9,(08), 55849-55853.

12. Dalan R, Earnest A, Leow MKS. Ethnic variation in the correlation between fasting glucose concentration and glycated hemoglobin $\left(\mathrm{HbA}_{1 \mathrm{c}}\right)$. Endocrine Practice 2013:1-16

13. Sharifi F, Sazandeh Sh. Serum ferritin in type 2 diabetes mellitus and its relationship with $\mathrm{HbA}_{1 \mathrm{c}}$. Acta Medica Iranica 2004;42(2):142-45

14. Abou-Shousha SA, El-Megeed MHA, Sultan HK. Interleukin, ferritin and soluble transferrin receptors in type 2 diabetes mellitus. The Egyptian Journal of Immunology 2006;13(1):19-25

15. Shetty JK, Prakash M, Ibrahim MS. Relationship between free iron and glycated hemoglobin in uncontrolled type 2 diabetes patients associated with complications. Ind J Clin Bio 2008;23(1):67-70

16. Kim NH et al. Serum ferritin in healthy subjects and type 2 diabetic patients. Yonsei Med J 2000;41(3):387-92. 